\title{
Germination, Growth, Photosynthesis, and Osmotic Adjustment of Tossa Jute (Corchorus olitrius L.) Seeds under Saline Irrigation
}

\author{
Amira Racha Ben Yakoub ${ }^{1,2 *}$, Samir Tlahig ${ }^{1}$,Ali Ferchichi ${ }^{3}$ \\ ${ }^{1}$ Arid and Oases Cropping Laboratory, Institute of Arid Lands (IRA), Médenine, Tunisia \\ ${ }^{2}$ Faculty of Sciences of Tunis, University Campus, El Manar, Tunisia \\ ${ }^{3}$ National Institute of Agronomy, Mahrajène City, Tunis, Tunisia
}

Received: 15 January 2018

Accepted: 12 February 2018

\begin{abstract}
A field experiment focusing on the response of Tossa jute (Corchorus olitorius L.) to salt stress at germination and vegetative growth stages was held in the Institute of Arid Lands of Medenine, Tunisia. Results showed that germinating rate after $24 \mathrm{hrs}$ exceeded $50 \%$ under salt levels between 0 and 5 g. $1^{-1}$. Indeed, salt stress levels delayed the initiation process and decreased significantly kinetics and rate of germination, which were severely limited at 9 and $10 \mathrm{~g} \cdot \mathrm{l}^{-1} \mathrm{NaCl}$. After one month of growth, Tossa jute seedlings were subjected to salt treatments of 2, 4, 6, and 8 g.l $1^{-1} \mathrm{NaCl}$. After four weeks of stress in pots, morphological responses were reflected by a significant decrease in parameters of growth and yield when salinity reached 8 g. $1^{-1}$. Indeed, a reduction in the photosynthetic gaseous exchange and a stomata resistance were notified for seedlings subjected to 6 and 8 g..$^{-1} \mathrm{NaCl}$ treatments. However, in order to tolerate the highest levels of salt, Tossa jute seedlings make different strategies by reducing the size of leaves, which increases their accumulation of osmolytes such as proline $\left(3.1 \mathrm{mg} \cdot \mathrm{g}^{-1} \mathrm{DM}\right)$ and soluble sugars (13.22 $\left.\mu \mathrm{g} \cdot \mathrm{g}^{-1} \mathrm{FM}\right)$ to permitting the osmotic adjustment.
\end{abstract}

Keywords: Corchorus olitorius, salinity, germination, growth, yield

\section{Introduction}

Tossa jute (Corchorus olitorius L.) is an annual vegetable crop belonging to the Tiliaceae family and Corchorus genus. This annual dicotyledonous species originated in Africa and was cultivated to provide bark

*e-mail: amirabenyakoub@gmail.com for fiber fabrication and mucilaginous leaves that are consumed for food as 'Mloukiya' in Arabic countries, where they are consumed either fresh or dried [1]. It is an important green leafy vegetable in many tropical areas, including Egypt, Sudan, India, Bangladesh, and the Caribbean, in tropical Asia such as the Philippines and Malaysia, and in North Africa and the Middle East, including Lebanon, Palestine, Syria, Jordon, Tunisia, Turkey, and Cyprus [2]. The distribution of Tossa jute in 
arid-regions is probably attributed to its tolerance to some environmental conditions such as water and soil salinity [3]. However, it has been noted that the production quality of this economical crop is affected by several abiotic factors, e.g., salinity and drought stress [4]. Salt stress is considered one of the main limiting factors affecting plant productivity worldwide and influences almost all aspects of plant biology. The effects of salinity on plant growth and yield are complex, and may result from a combination of toxic, nutritional, and osmotic factors [5]. Unfavorable effects of salinity have been reported by Shila et al. [6], who observed that the amplification in the concentration of salt harmfully affected seed germination and caused a decrease in germinability and delayed rate of germination of sunflower. Salinization can also influence the growth and almost every aspect of the physiology of plants and significantly reduce plant production [7]. Due to this situation, increasing tolerance to salt stress in crop plants is necessary in order to increase yield [4]. The tolerance of plants to salt condition is a complex phenomenon that implies specific morphological and developmental mechanisms with physiological and biochemical change [8]. In this situation of stress, the responses differ between plants, which can react by a reduction in leaf size, the increase of leaf thickness and stomatal length and develop adaptation, i.e., succulence, osmotic adjustment, salt glands, and ionic compartmentation to dilute or counter-balance the effect of hypersalinisation [4,7]. For clarifying and improving the mechanism of salt tolerance, it is necessary to identify the physiological and biochemical response to salinity. Yet in Tunisia, the comportment of C. olitorius to salinity condition has not been assessed well. Therefore, this study aimed to test salt tolerance in Tossa jute and the threshold level of tolerance at germination and vegetative growth stages in order to identify the physiological and agro-morphological traits affected by this abiotic stress.

\section{Materials and Methods}

\section{Plant Material}

Seeds of $C$. olitorius collected from Gabes oasis in southeastern Tunisia $(33.50 \mathrm{~N}, 10.06 \mathrm{E}, 16 \mathrm{~m}$ a.s.1) were used in these experiments. The trial was carried out from June to August (year) in the Arid and Oases Cropping Laboratory, Institute of Arid Lands (IRA), Medenine, Tunisia.

\section{Experiment 1}

\section{Germinating Tossa Jute Seeds under Saline Conditions}

Before germination, seeds placed on 2 layers of filter paper in Petri dishes were soaked in water at $100^{\circ} \mathrm{C}$ with sulphuric acid for $5 \mathrm{~min}$ and then they were repeatedly washed with distilled water. The sterilized seeds with bleach $50 \%(\mathrm{v} / \mathrm{v})$ for $3 \mathrm{~min}$ were allowed to germinate in a growth chamber at $25^{\circ} \mathrm{C}$. For this, 20 viable seeds were distributed into Petri dishes; lined a double filter paper wetted each with $0.5 \mathrm{ml}$ of $0,1,2,3,4,5,6,7$, 8, 9, and 10 g.l - $^{-1} \mathrm{NaCl}$ solutions $\left(\mathrm{T}_{0}, \mathrm{~T}_{1}, \mathrm{~T}_{2}, \mathrm{~T}_{3}, \mathrm{~T}_{4}, \mathrm{~T}_{5}\right.$, $\mathrm{T}_{6}, \mathrm{~T}_{7}, \mathrm{~T}_{8}, \mathrm{~T}_{9}$, and $\mathrm{T}_{10}$, respectively ). During 14 days the numbers of germinated seeds were counted daily and five replications for each treatment were applied. A seed was considered to have germinated when its radical emerged [6].

The measured parameters are:

- Final germination capacity: the percentage of seeds that germinate under well-defined conditions.

- Germination kinetics: the time taken by the germination of $50 \%$ of seeds and the number of days to start germination (L: delay of the initiation of germination).

\section{Experiment 2}

\section{Effect of Salt Irrigation Treatments on Growth and Yield}

Growth condition

Before planting, seeds were treated with sulphuric acid. The sterilized seeds with bleach $50 \%(\mathrm{v} / \mathrm{v})$ for 5 min were allowed to germinate at $25^{\circ} \mathrm{C}$ in peat and watered every three days. Transplanting was undertaken when the seedling reached the three-leaf stage; each single seedling was placed in a $12 \mathrm{~cm}$ diameter plastic pot perforated at the bottom to enhance drainage without depleting soil quality, and filled with a uniform soilpeat mixture in $2 / 3: 1 / 3$. Plants were irrigated two times weekly and grown in a greenhouse $\left(25^{\circ} \mathrm{C}\right.$ and natural lighting photoperiod of 10 hours).

\section{Salinity treatments}

Four salt $(\mathrm{NaCl})$ treatments $\left(\mathrm{T}_{0: 2}\right.$ g. $\mathrm{l}^{-1}$ (control), $\mathrm{T}_{1}: 4 \mathrm{~g} . \mathrm{l}^{-1}, \mathrm{~T}_{2}: 6 \mathrm{~g} . \mathrm{l}^{-1}$ and $\left.\mathrm{T}_{3}: 8 \mathrm{~g} . \mathrm{l}^{-1}\right)$ were applied since the fourth week following the seedlings emergence four weeks after emergence.

Salt concentrations were chosen referring to the concentrations of the irrigation waters in southern Tunisia, which differs among regions.

\section{Experimental design}

Individual plants presenting homogeneous development and size were selected for this trial. The experiment was arranged in four lines of completely random design (CRD), with eight replicates of each treatment. An additional number of pots were used for possible replacement on failure.

\section{Assessed parameters}

For the following measurements, eight samples per treatment obtained from the youngest fully expanded leaves after 30 days of the trial were evaluated regarding their: 
- Parameters of growth

During the experimental period, eight agro-morphological traits were assessed. For each single seedling, evaluations concerned plant height $(\mathrm{cm})$, the number of ramifications/plants, the number of leaves/plants (counted), leaf area $\left(\mathrm{cm}^{2}\right)$, the number of pods/plants (counted), lengths of pods $(\mathrm{cm})$, and the number of seeds/pods (counted). During the last day of the experiment, eight mature leaves per treatment were gathered to measure leaf area $\left(\mathrm{cm}^{2}\right)$, which was obtained by image processing using Mesuruim software. At the end of the experiment, destructives analyses were done by harvesting the plants according to treatment. Samples collected were labeled and taken to the laboratory for data collection. Leaf fresh matter and total fresh matter were weighed. Samples were dried in an oven at $80^{\circ} \mathrm{C}$, and after $48 \mathrm{~h}$ the leaf dry weigh per plant $(\mathrm{g})$ was determined using a precision balance.

- Gas exchange measurements

Before harvesting, photosynthetic traits were measured in situ on mature fully sun-exposed leaves during the late morning (10:00-11:00) with an Lci portable measurement device of photosynthesis. Light saturated net photosynthetic rate (A), stomatal conductancy (gs), and transpiration (E) were quantified.

- Soluble sugars and proline accumulation

Accumulated proline content was determined referring to the method of Bates et al. [9]. Soluble sugar concentrations were quantified using the phenol method of Dubois et al. [10].

\section{Statistical Procedures}

Statistical analyses were performed using XLSTAT software. Data were subjected to one-way analysis of variance (ANOVA) to test differences among the salt treatments during germination and vegetative growth stages. Significant differences were considered at $P<0.05$.

\section{Results}

\section{Effect of Salt Treatments on Seeds Germination}

ANOVA revealed significant differences in seed germination between the ten concentrations of salt solutions imposed. Seeds of C. olitorius emerged in all $\mathrm{NaCl}$ concentrations (Fig. 1). However, the speed of germination decreased proportionally when salt level was raised. Grains germinated rapidly after $24 \mathrm{~h}$ in solutions between 0 and 6 g. $1^{-1} \mathrm{NaCl}$, and the highest germination percentage was found in distilled water, followed by salt solutions between 1 and 5 g. l. $^{-1}$. Full seed germination (100\%) was reached after two days for $\mathrm{T}_{0}$ and $\mathrm{T}_{1}$, after three days for $\mathrm{T}_{2}, \mathrm{~T}_{3}$, and $\mathrm{T}_{4}$, and four days for $T_{5}$ treatments. However, from the application of $\mathrm{T}_{6}$ we marked a significant reduction in speed and rate germination that was severely limited at 9 and 10 g. $1^{-1}$ (Fig. 1; $P<0.05$ ). Indeed, after 2 weeks of salt treatment applications, the final percentage of germination decreased by $47,60,69$, and $83 \%$ under $\mathrm{T}_{7}, \mathrm{~T}_{8}, \mathrm{~T}_{9}$, and $\mathrm{T}_{10}$ compared to control treatment. The increase in $\mathrm{NaCl}$ concentrations prolonged the lag time before the germination (L) and delayed the germination rate $\mathrm{t}(50)$ (Fig. $1 ; P<0.05$ ). L was prolonged from one to three days for treatments $\mathrm{T}_{9}$ and $\mathrm{T}_{10}$ compared to other salt regimes. The delay of germination prolonged with increasing salt concentrations. However, the $\mathrm{t}$ (50) was delayed for one day for the treatments between $\mathrm{T}_{0}$ and $\mathrm{T}_{5}$ to two days for $\mathrm{T}_{6}$ and eight days for $\mathrm{T}_{7}$. Above $\mathrm{T}_{7}$, the germination rate is less than $50 \%$.

\section{Effect of Salt Irrigation Treatment on Morphological Parameters}

\section{Vegetative Growth}

The effect of salinity regimes on growth performances of $C$. olitorius was assessed during this trial. Fig. 2 represents the growth of $C$. olitorius plants under different salt regimes. Statistical analysis showed a significant difference between salt treatments $(P<0.05)$. The highest growth potentials were observed for control plants receiving the treatment $\mathrm{T}_{0}$. The stem lengths decreased when the level of salt stress increased. This effect is more remarkable regarding the treatment duration. Indeed, at the end of the treatment period, plant height was significantly inhibited by the salinity treatment $\mathrm{T}_{2}$ (6 ${\left.\mathrm{g} . \mathrm{l}^{-1}\right)}^{-1}$ by $30.23 \%$. This depressive effect was moremarked in plants irrigated with the severe treatment

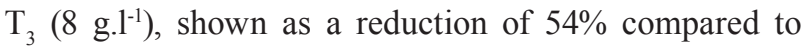
control plants $\mathrm{T}_{0}\left(2\right.$ g..$\left.^{-1}\right)$.

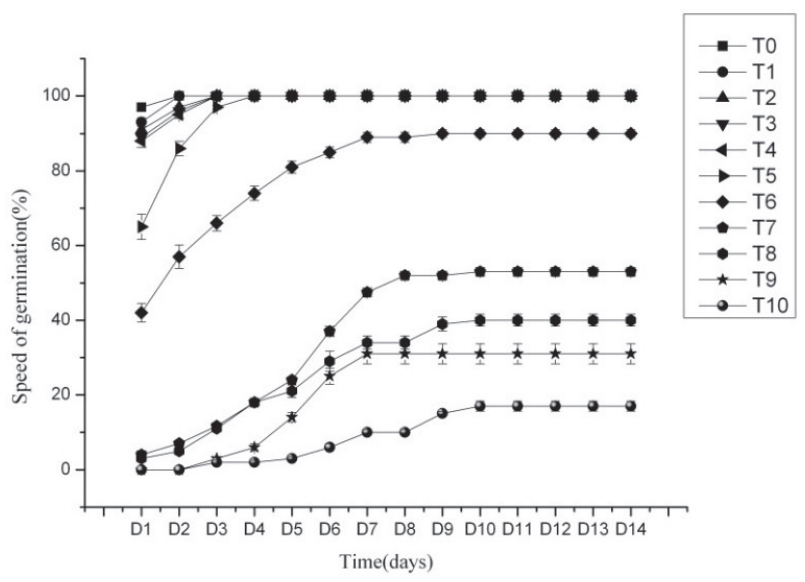

Fig. 1. Germination speed under salt treatments from 0 to $10 \mathrm{~g} . \mathrm{l}^{-1}$ in C. olitorius seeds;

*letters (a, b, c...) following curves were given by Duncan test $(P<0.05)$ applied on cumulated germinations after 14 days 


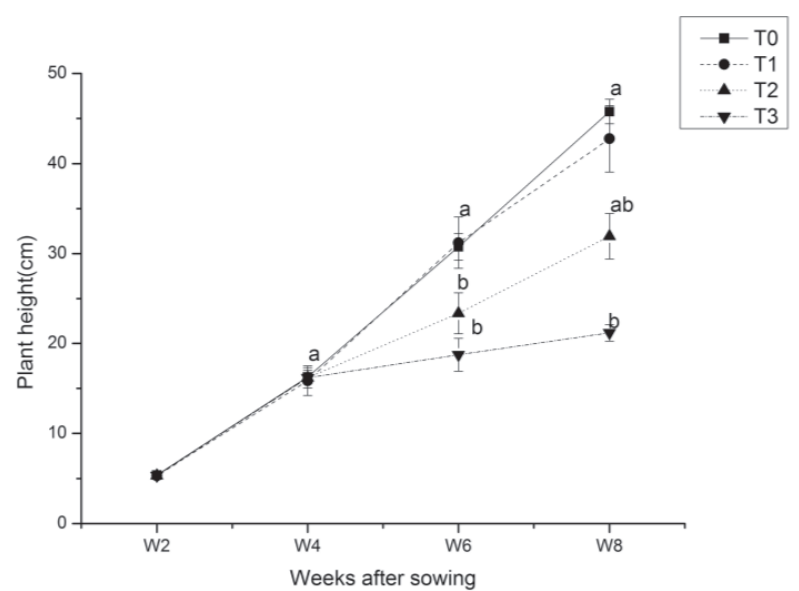

Fig. 2. Effect of salt treatments on growth of C. olitorius when 1-month-old plants were subjected to salinity treatments of $\left(\mathrm{T}_{0}\left(2 \mathrm{~g} . \mathrm{l}^{-1}\right), \mathrm{T}_{1}\left(4 \mathrm{~g} . \mathrm{l}^{-1}.\right), \mathrm{T}_{2}\left(6 \mathrm{~g} . \mathrm{l}^{-1}\right)\right.$, and $\mathrm{T}_{3}\left(8 \mathrm{~g} \cdot \mathrm{l}^{-1}\right) \mathrm{NaCl}$;

*different letters above bars are significantly different at the $P=0.05$ level for the given salt watering regimes (mean $\pm 95 \%$ confidence limits)

\section{Yield Parameters}

Results of yield traits assessed after one month of salt treatments are represented in Table 1. The number of ramifications per plant was affected by salinity levels. At the end of treatments $\mathrm{T}_{2}$ and $\mathrm{T}_{3}$, significant reductions of 51.17 and $56.44 \%$, respectively, compared to treatment $\mathrm{T}_{0}$ were noted. However, no significant difference was noted when applying the treatment $\mathrm{T}_{1}$

Numbers of green leaves per plant were also significantly influenced under salt irrigation conditions (Table $1 ; P<0.05$ ). Plants receiving the regime $\mathrm{T}_{0}$ have the highest number of leaves (40 leaves per plant). Irrigation using salty water decreased leaf formation as the stress was intensified. Symptoms of salt stress were displayed on seedlings mainly in higher concentrations of $\mathrm{NaCl}$. The number of leaves was not significantly different with increasing salinity between $T_{0}$ and $T_{1}$. Under treatment $T_{3}$, leaves become twisted and tightly rolled and the tips of older leaves became yellowish. The formation of new leaves was decreased and the numbers of senescent leaves was the biggest. These effects caused a significant reduction of $63.5 \%$ in the number of leaves formed compared with the control treatment. The salinity levels also affect leaf size (Table 1). There were significant differences $(\mathrm{P}<0.05)$ between mean leaf areas at moderate $\left(\mathrm{T}_{2}\right)$ and severe $\left(\mathrm{T}_{3}\right)$ salinity treatments. The leaf area of $\mathrm{C}$. olitorius was decreased as the level of salinity was amplified. At the end of the application of treatment $\mathrm{T}_{2}$, we noted a significant reduction of $46.48 \%$ compared to control regime $\mathrm{T}_{0}$. Applying the treatment $\mathrm{T}_{3}$, this decline attains 68.7\% $(P<0.05)$.

The yield of $C$. olitorius was adversely affected as the salinity regimes increased and we marked a significant reduction compared to control plants (Table 1; $P<0.05$ ). The response of Tossa jute to salinity regimes monitored via their total fresh mass production and fresh and dry mass leaves production are shown in Table 1. Indeed, after 30 days of salt irrigation, the total fresh mass production was inversely proportional to the increase of salinity levels and a reduction of $40.45 \%$ after treatment $\mathrm{T}_{3}$ compared to $\mathrm{T}_{0}$ was observed. The fresh leaf production was significantly lower above $8 \mathrm{~g} \cdot \mathrm{l}^{-1} \mathrm{NaCl}$ when compared to control seedlings. The treatments $\mathrm{T}_{2}$ and $\mathrm{T}_{3}$ caused a reduction of 34.54 and $54.47 \%$, respectively, compared to treatment $\mathrm{T}_{0}$ (Table $1 ; P<0.05$ ). Plants receiving treatment $\mathrm{T}_{0}$ had the highest mean fresh and dry leaf weights. There were significant differences at different salinity levels. In fact, under control treatment $\left(\mathrm{T}_{0}\right)$, dry weight reached $4.1 \mathrm{~g}$ per plant. This value was reduced to $1.24 \mathrm{~g}$ per plant at $\mathrm{T}_{3}$.

The response of seed yield of C. olitorius to the varying salt concentrations is represented in Table 1.

Table 1. Growth and yield parameters of $C$. olitorius after four weeks of salt treatment $\left(\mathrm{T}_{0}\left(2 \mathrm{~g} . \mathrm{l}^{-1}\right), \mathrm{T}_{1}\left(4 \mathrm{~g} . \mathrm{l}^{-1}\right), \mathrm{T}_{2}\left(6 \mathrm{~g} \cdot \mathrm{l}^{-1}\right)\right.$, and $\mathrm{T}_{3}\left(8 \mathrm{~g} \cdot \mathrm{l}^{-1}\right)$ $\mathrm{NaCl}$.

\begin{tabular}{|c|c|c|c|c|}
\hline $\mathrm{NaCl}\left(\mathrm{g} . \mathrm{l}^{-1}\right)$ & $\mathrm{T}_{0}$ & $\mathrm{~T}_{1}$ & $\mathrm{~T}_{2}$ & $\mathrm{~T}_{3}$ \\
\hline Number of ramifications & $10.62 \pm 0.7^{\mathrm{a}}$ & $10 \pm 1.41^{\mathrm{a}}$ & $5.12 \pm 0.83^{\mathrm{b}}$ & $4.62 \pm 0.9^{\mathrm{b}}$ \\
\hline Number of leaves & $40.75 \pm 2.6^{\mathrm{a}}$ & $35.12 \pm 1.95^{\mathrm{a}}$ & $21.75 \pm 2.51^{\mathrm{b}}$ & $14.87 \pm 1.12^{\mathrm{c}}$ \\
\hline Leaves area $\left(\mathrm{cm}^{2}\right)$ & $12.22 \pm 1.3^{\mathrm{a}}$ & $11.62 \pm 0.51^{\mathrm{a}}$ & $6.54 \pm 1.0^{\mathrm{b}}$ & $3.82 \pm 0.46^{\mathrm{c}}$ \\
\hline Total fresh mass production (g) & $42.19 \pm 3.8^{\mathrm{a}}$ & $37.5 \pm 5.29^{\mathrm{b}}$ & $29.82 \pm 1.4^{\mathrm{c}}$ & $25.12 \pm 2.36^{\mathrm{d}}$ \\
\hline Leaf fresh mass production (g) & $9.38 \pm 1.25^{\mathrm{a}}$ & $8.12 \pm 1.03^{\mathrm{b}}$ & $6.14 \pm 1.4^{\mathrm{c}}$ & $4.27 \pm 0.46^{\mathrm{d}}$ \\
\hline Leaf dry mass production (g) & $4.1 \pm 0.86^{\mathrm{a}}$ & $3.06 \pm 0.53^{\mathrm{b}}$ & $2.2 \pm 0.7^{\mathrm{c}}$ & $1.24 \pm 0.28^{\mathrm{d}}$ \\
\hline Number of pods/plant & $11.87 \pm 0.99^{\mathrm{a}}$ & $10.12 \pm 1.55^{\mathrm{b}}$ & $7.87 \pm 0.99^{\mathrm{c}}$ & $6 \pm 0.92^{\mathrm{d}}$ \\
\hline Lengths of pods (cm) & $6.85 \pm 1.15^{\mathrm{a}}$ & $6.7 \pm 1.26^{\mathrm{a}}$ & $6.5 \pm 1^{\mathrm{a}}$ & $4.25 \pm 0.58^{\mathrm{b}}$ \\
\hline Number of seeds/ pods & $155.62 \pm 10.9^{\mathrm{a}}$ & $141 \pm 23.13^{\mathrm{ab}}$ & $139.75 \pm 11.2^{\mathrm{b}}$ & $97.12 \pm 9.64^{\mathrm{c}}$ \\
\hline
\end{tabular}

${ }^{*}$ Superscript letters with different letters in the same line indicate significant differences, $(\mathrm{P}<0.05)$ analyzed by Fisher's multiple range test. 
a)

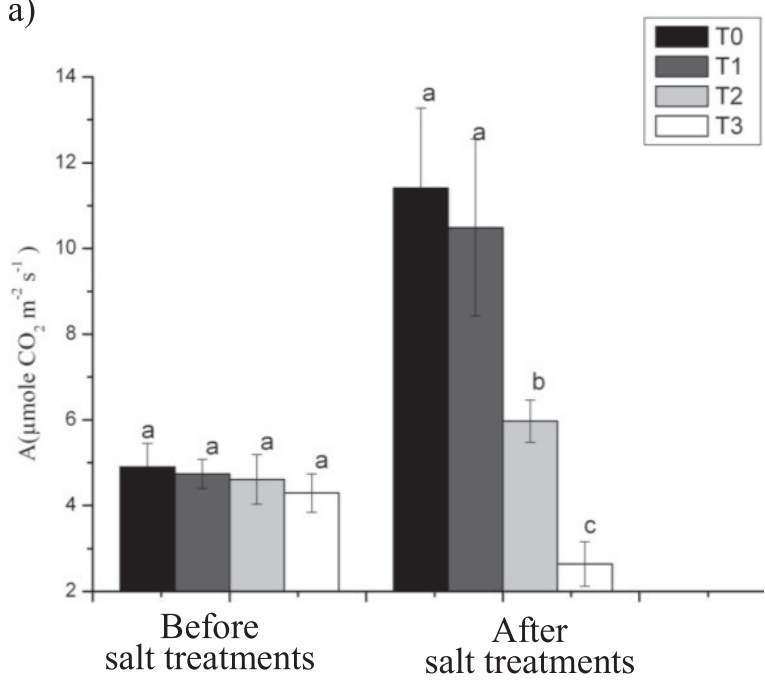

b)

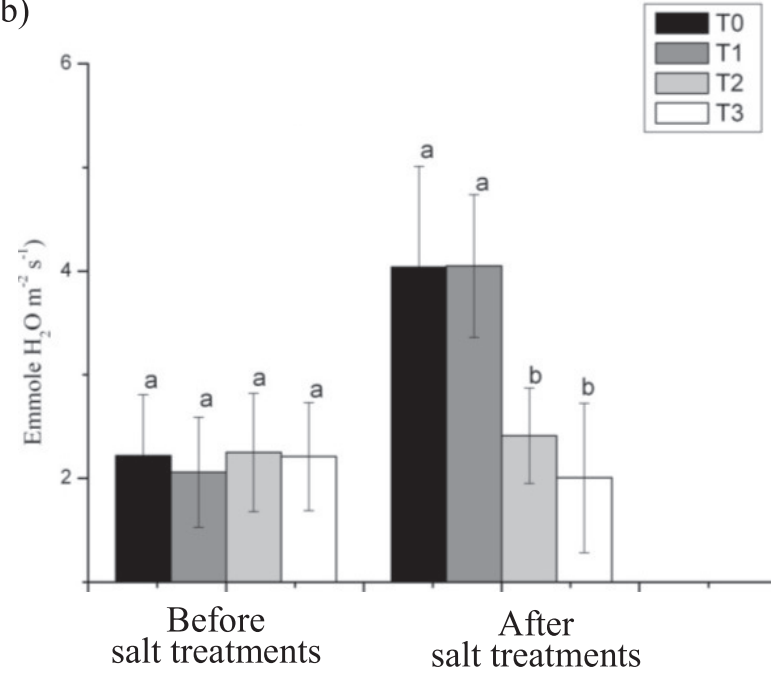

c)

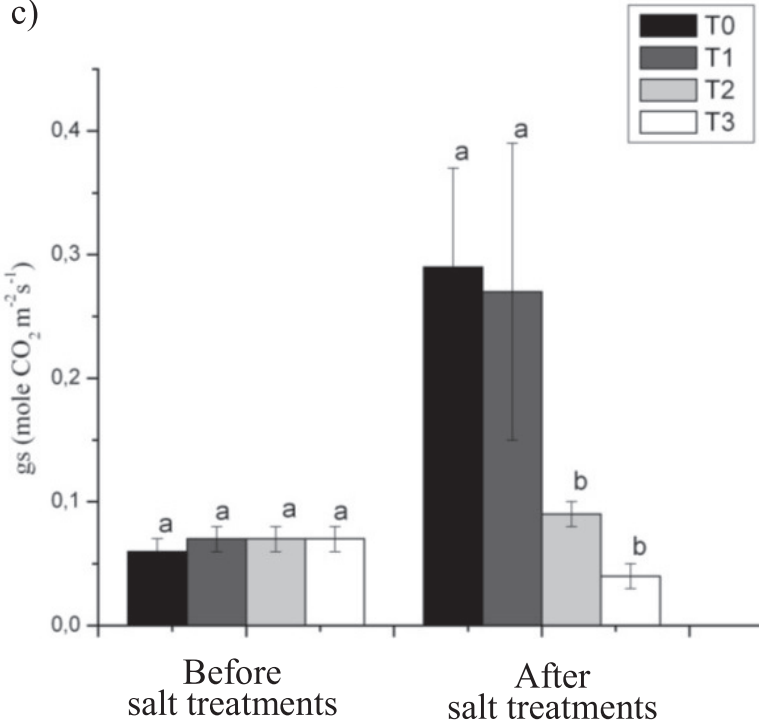

Fig. 3. Effect of salt treatments on photosynthetic gaseous exchange of $C$. olitorius when 1-month-old plants were subjected for four weeks to $\mathrm{NaCl}$ treatments; $\mathrm{A}_{\max }$ : light-saturated net photosynthetic Rate; E: transpiration rate; gs: stomatal conductance; *different letters above bars are significantly different at the $P=0.05$ level for the given salt watering regimes (mean $\pm 95 \%$ confidence limits)
The number of pods was affected by salt irrigation. The maximum of fruits produced was obtained on control plants (12 pods per plant) and we marked a significant differences between the moderate $\left(T_{2}\right)$ and severe $\left(\mathrm{T}_{3}\right)$ treatments, which reached their lowest values (Table $1 ; P<0.05$ ). The effect of salinity on pod length of $C$. olitorius showed differences between the mean pod lengths when applying the severe treatment $\mathrm{T}_{3}$ (Table 1; $P<0.05)$. This result was also observed in mean number of seeds/pod, and we noted a reduction of $37 \%$ of seed yield under treatment $\mathrm{T}_{3}$ compared to controls plants.

\section{Effect of Salt Irrigation Treatments on Photosynthetic and Transpiration Rates}

The effect of salt watering regimes was observed on net photosynthetic rates (A), transpiration rate (E), and stomatal conductance (gs) as shown in Fig. 3. Four weeks after applying salt treatments, the plants' fully sunexposed leaves of Tossa jute showed different patterns. Net photosynthetic rate was lowered when exposed to $T_{2}$ and $\mathrm{T}_{3}$ treatments and marked a reduction of 45.92 and $75.96 \%$, respectively, compared to control treatment $\mathrm{T}_{0}$ (Fig. 3a); $P<0.05$ ).

The transpiration rate decreased with intensifying salt levels. Indeed, leaves of plants subjected to the treatments $\mathrm{T}_{2}$ and $\mathrm{T}_{3}$ present low values compared to $\mathrm{T}_{0}$. At the end of the salt irrigation, plants receiving the treatment $\mathrm{T}_{1}$ reveled less reduction in $\mathrm{E}$ than plants receiving the treatment $\mathrm{T}_{2}(40.34 \%)$ and $\mathrm{T}_{3}(50.49 \%$ ) (Fig. 3b); $\mathrm{P}<0.05$ ). With amplifying salt levels, stomatal conductance values of C. olitorius seedlings decreased between the $\mathrm{NaCl}$ levels of 4,6 , and 8 g..$^{-1}$, respectively $6.89,66.55$, and $86.2 \%$ compared to treatment $\mathrm{T}_{0}$ (Fig. 3 c); $P<0.05$ )

\section{Effect of Salt Irrigation Treatments on Osmotic Adjustment}

As shown in Table 2, the amount of proline and soluble sugar accumulation in leaves was dependent on salt levels. Salt stress induced an accumulation in proline content, which increased with amplifying the salt intensity to sustain the osmotic potential and maintain a flow of water into the plant $(P<0.05)$. Indeed, at the end of the salinity treatment, plants submitted to treatment $\mathrm{T}_{3}$ accumulated $3.1 \mathrm{mg} \cdot \mathrm{g}^{-1} \mathrm{DM}$. The accumulation of soluble sugars exhibited different responses to salt intensities. Statistical analysis showed a significant difference between salt regimes $(\mathrm{P}<0.05)$. Four weeks of salinity treatment tended to increase the accumulation of soluble sugars. This stimulation is about 56.28 and $72 \%$, respectively, under irrigation with $\mathrm{T}_{2}$ and $\mathrm{T}_{3}$ treatments compared to treatment $\mathrm{T}_{0}$.

\section{Discussion}

Tolerance to abiotic stresses is very complex due to the intricate interactions between stress factors and various 
Table 2. Effect of different salinity treatments on accumulation of proline and soluble sugars in C. olitorius leaves after one month of salt irrigation $\left(\mathrm{T}_{0}\left(2 \mathrm{~g} \cdot \mathrm{l}^{-1}\right), \mathrm{T}_{1}\left(4 \mathrm{~g} \cdot \mathrm{l}^{-1}\right), \mathrm{T}_{2}\left(6 \mathrm{~g} \cdot \mathrm{l}^{-1}\right)\right.$ and $\mathrm{T}_{3}\left(8 \mathrm{~g} \cdot \mathrm{l}^{-1}\right) \mathrm{NaCl}$.

\begin{tabular}{|c|c|c|c|c|}
\hline $\mathrm{NaCl}\left(\mathrm{g} \cdot \mathrm{l}^{-1}\right)$ & $\mathrm{T}_{0}$ & $\mathrm{~T}_{1}$ & $\mathrm{~T}_{2}$ & $\mathrm{~T}_{3}$ \\
\hline Proline $\left(\mathrm{mg} \cdot \mathrm{g}^{-1} \mathrm{DM}\right)$ & $0.2 \pm 0.089^{\mathrm{c}}$ & $0.23 \pm 0.66^{\mathrm{c}}$ & $0.82 \pm 0.24^{\mathrm{b}}$ & $3.1 \pm 0.5^{\mathrm{a}}$ \\
\hline Soluble sugars $\left(\mu \mathrm{g} \mathrm{g}^{-1} \mathrm{FM}\right)$ & $3.62 \pm 0.5^{\mathrm{c}}$ & $3.7 \pm 0.43^{\mathrm{c}}$ & $8.28 \pm 0.8^{\mathrm{b}}$ & $13.22 \pm 0.3^{\mathrm{a}}$ \\
\hline
\end{tabular}

${ }^{*}$ Superscript letters with different letters in the same line indicate significant difference; $(\mathrm{P}<0.05)$ analyzed by Fisher's multiple range test

molecular biochemical and physiological phenomena affecting plant growth and development [12]. To improve tolerance and increase yield to salt conditions in crop plants, it is important to understand its responsive mechanism from germination to vegetative growth [5, 13]. Salt tolerance is a complex trait that involves numerous genes and various physiological, and biochemical mechanisms [14]. C. olitorius is an annual plant native to the semi-arid tropics, temperate regions, and lowland areas of Africa and Asia, and serves as an important source of nutrients for indigenous populations. In these regions, salt stress is the main factor limiting plant development. Currently, little information is available regarding the relative salt tolerance of this plant in different stages of development. The present experiment allowed for a detailed analysis on responses of C. olitorius in southern Tunisia under salt treatments in germination and vegetative growth stages. Tolerance to salinity during germination is critical for the establishment of plants of saline conditions. This is based on the percentage of surviving seeds. Based on the previous studies, halophyte seeds can survive and develop some adaptation that distinguishes them from glycophyte seeds, which the hypersaline conditions lead to a reduction and a delay in their germination [11]. In our conditions, exposure to $\mathrm{NaCl}$ stress between 0 and 10 g. $\mathrm{l}^{-1}$, we found a significant difference $(P<0.05)$ in germination aptitude and a delay in the initiation of this process (Fig. 1). Seed germination attains the maximum in distilled water and is sensitive to high salinity levels. Indeed, salt watering regimes between 0 and 5 g. $1^{-1} \mathrm{NaCl}$ allow for a percentage of germination that exceeded $50 \%$ after 24 hours and reached $100 \%$ after a period between two to four days. However, salinity between 7 and 10 g.l.$^{-1}$ caused a significant reduction in rate and speed germination in which they were severely limited at 9 and 10 g. $1^{-1} \mathrm{NaCl}$ (Fig. $1 ; P<0.05$ ). The increase of salt concentration prolonged the lag time before germination (L) from one day for the treatment between $\mathrm{T}_{0}$ and $\mathrm{T}_{8}$ to three days for the treatments $\mathrm{T}_{9}$ and $\mathrm{T}_{10}$ and delayed the germination rate $t$ (50) from one day for the treatment between $T_{0}$ and $T_{5}$ to eight days for treatment $\mathrm{T}_{7}$. However, the salinity from $8 \mathrm{~g} .1^{-1} \mathrm{NaCl}$ allows for a germination that does not reach $50 \%$ (Fig. 1). In this context, Taneenah et al. [4], showed that the germination percentage and relative germination rate of C. olitorius seeds with sea water and $\mathrm{NaCl}$ were significantly reduced with the increased percentage of salinity. Thus, it is thought that increasing the percentage of salt causes osmotic pressure increasing in C. olitorius seeds that eventually allows for entry of water into the seed, which also decreased. Therefore, the widespread level of tolerance to the low concentration and the high percentage of germination of seeds at 3\%o of seawater is an indication that the exclusion of C. olitorius from a saline environment cannot mainly be the result of any negative effect of salinity on seed germination. However, seeds treated at high levels of salinity that failed to germinate at a salinity of lower levels may be important in the exclusion of species from the saline environment. Indeed, the inhibition effect during germination is attributed to both osmotic and salt toxic effects. In the same context, Syvertsen and Garcia-Sanchez [13] explain that the germination rate in citrus was mainly affected by the osmotic effect of the medium and secondarily by its ionic effect. Our results reveal important reductions in germination rates in those seeds subjected to the highest salt levels (above 8 g..$^{-1} \mathrm{NaCl}$ ). This can indicate that seed osmotic adjustment was influenced and that severe salt stress favored the entering of other ions into the seeds. Our results in this study are similar to earlier findings of Bhagirath and Johnson [15], which confirms that the germination of $\mathrm{C}$. olitorius exceeded $87 \%$ when exposed to $150 \mathrm{mM} \mathrm{NaCl}$ and can be germinated even at $250 \mathrm{mM}$. These results indicate that, in saline conditions, Tossa jute may germinate, which could be a key feature of this species when colonizing moderately saline areas.

The present experiment also allowed us a detailed analysis on responses of C. olitorius under four salt treatments during 30 days. The responses of plants to excess $\mathrm{NaCl}$ are complex and make changes in their morphology, physiology, and metabolism. In our conditions, the occurrence of salt regimes has a more profound effect on morphological parameters on Tossa jute. In exposure to higher levels of salt stress, we found a significant difference $(P<0.05)$ in plant growth. There was a significant decrease in mean plant height and number of ramifications per plant as salinity levels increased. Mean growth of the control plant receiving the treatment $T_{0}$ was highest, and we marked a large reduction for the treatments $T_{2}$ and $T_{3}$ (Fig. 2). In the same context, Ouzounidou et al. [7] showed that under saline concentrations of 50 and $100 \mathrm{mg} / \mathrm{l}$, the growth rate of Vicia faba was significantly reduced with fewer fruiting branches. This result can explain that salinity stress reduces the ability of a plant to use water and cause a reduction in growth rate, as well as a hyperosmotic stress and consequently a perturbation 
in plant metabolism processes [13]. Besides, Taneenah et al. [4] suggested that the reduction in shoot growth is due to high salt levels commonly expressed by a reduced leaf growth and stunted shoots. Our results expressed this result by a reduction in the number of leaves formed and their size (Table 1). This depressive effect is more marked by the application of treatment $\mathrm{T}_{3}$ in comparison with plans receiving the levels $\mathrm{T}_{0}$, which presents the best potentiality of leaf growth. This similar effect was observed on leaves of C. olitorius, which sees moderate salt stress of $(0.15 \% \mathrm{NaCl})$, causing a significant decrease in number and leaf size [16].

On the other hand, the means performance of $\mathrm{C}$. olitorius yield illustrated that the best results were observed in treatment $\mathrm{T}_{0}$ (Table 1). Leaf dry weight and total dry weight of plants irrigated by $\mathrm{T}_{0}$ are significantly greater than those receiving treatments $T_{2}$ and $T_{3}$. In this context, Javed et al. [17] indicate that the increase in salinity caused a decrease in fresh and dry mass of safflower (Carthamus Tinctorius). A similar inhibitory effect of $\mathrm{NaCl}$ was observed on reproductive traits and influenced seed yield. There were significant differences on the number and length of pods per plant and the number of seeds per pod when the salinity increased and the lowest seed yield was detected under treatment $\mathrm{T}_{3}$, which showed a reduction of $37 \%$ on seed yield compared to treatment $\mathrm{T}_{0}$. Our findings were similar to results reported by Ouzounidou et al. [7], who showed that salt stress negatively influences broad bean seeds and pod yields, with decreases attaining 53\%.

Photosynthesis is the process by which green plants and certain other organisms use the energy of light to convert carbon dioxide and water into simple sugar glucose. In doing so, photosynthesis provides the basic energy source for virtually all organisms. But the process of photosynthesis is a primary target of many forms of environmental stress, including salinity. Ours results shows that seedlings of Tossa jute subjected to treatments $T_{2}$ and $T_{3}$ showed a significant decline in their photosynthesis and transpiration traits after one month of salt irrigation (Fig. 3a,b). This answer agrees with the experiment of Chaudhuri and Choudhuri [18], who found that the net photosynthetic and transpiration rate of plants are greatly declined by the application of shortterm $\mathrm{NaCl}$ treatment during one day. In this context, Alam et al. [19] showed that gas exchange decreased as the levels of salinity increased. This reduction of intensity of photosynthesis in the presence of salt can be explicated by the dehydration of cell membrane, which reduces their permeability to $\mathrm{CO}_{2}$, and the inhibition of chlorophyll biosynthesis that may be caused by nutrient deficiency induction or imbalance [5]. As the transpiration is controlled by the closing and opening of the stomata, the declines of theses physiological characters reflects a stomata adjustment constituting an adaptation developed by this species. Consequently, this adjustment limits $\mathrm{CO}_{2}$ diffusion through the stomata, causing a decline in photosynthetic rates. The stomata conductance data in this study indicated a significant $(P<0.05)$ change by the application of $T_{2}$ and $T_{3}$ treatments, which showed a tolerance to salinity (Fig. 3c). Similar results were reported by Taneenah et al. [4], who suggested that the closure of stomata in hypersaline conditions is a way for plants to decrease in uptake of $\mathrm{CO}_{2}$ used in the carboxylation reaction and consequently to conserve water in the process of transpiration. Therefore, the stomatal pores initiation to closure and narrow, causing stoppage of $\mathrm{CO}_{2}$ uptake for photosynthesis and transpiration.

This decrease of photosynthetic gaseous exchange is under the possible effect of both leaf water potential and osmotic adjustment. During stress conditions plants need to maintain internal water potential below that of soil and maintain turgor. To balance the osmotic difference in the cells, cytoplasm stores up low molecule mass composites, the osmolytes which not interfere with normal biochemical reaction. Osmotic adjustment in terms of accumulating compatible solutes such as proline, soluble sugars, and glycine betaine has been considered as an important physiological adaptation for plants to resist stress, which facilitate extracting water and maintaining cell turgor, gas exchange, and growth in severe conditions [7, 20-21]. In this study, under saline conditions C. olitorius synthesizes organic solutes such as proline and soluble sugars. These organic solutes help maintain water potential below that of soil and thus maintain the osmotic balance and turgor pressure in saline conditions. Proline and carbohydrates are important osmolytes for adjusting the plant under both drought and salinity conditions and their accumulation increased in response to an excess of $\mathrm{NaCl}$ levels [7]. As their accumulation is proportional to external osmolarity, plants subjected to high salt levels amplify the accumulation of these osmolytes with the increasing salt. Biochemical analysis of leaves of Tossa jute for proline and soluble sugars indicated that their accumulation increased with increased salt stress (Table $2 ; P<0.05$ ). The highest content was found in plants subjected to the $T_{3}$ treatment. This similar comportment was also observed in Arachis hypogaea [21].

\section{Conclusion}

The overall results suggest that Tossa jute seeds can survive under saline conditions. They present a percentage of germination that reaches $100 \%$ under moderate salt treatment, and the germination was limited just under height levels of salt (9 and $\left.10 \mathrm{~g}^{\mathrm{l}} \mathrm{l}^{-1}\right)$. This result demonstrates salt tolerance during germination of $\mathrm{C}$. olitorius, which $\mathrm{NaCl}$ represents as a genetic material for surviving under high salt levels.

Improving salinity tolerance would be of significant value for this moderating sensitive crop when it is grown on lands with salinity problems. Indeed, the application of $8.1^{-1}$ negatively affects the majority of agro-morphological, physiological, and yield traits of Tossa jute, but some tolerance strategies were observed, showing a strong plasticity adaptive to salinity. At the morphological level, 
plants submitted to moderate $\left(\mathrm{T}_{2}\right)$ and severe $\left(\mathrm{T}_{3}\right)$ salinity levels decrease the number of leaves and branches and minimize leaf size. At physiological, to avoid excessive salt intensity plants exploit a stomata adjustment. Osmotic adjustment in terms of accumulating amino acid proline and sugars is considered an important physiological adaptation for Tossa jute to resist excess salt levels.

\section{Conflict of Interest}

The authors declare no conflict of interest.

\section{References}

1. ISLAM M.M. Biochemistry, Medicinal and Food values of Jute (Corchorus capsularis L. and C. olitorius L.) leaf. Int. J. Enhanced Res. Sci. Technol. Eng. 2 (11), 35, 2013.

2. MUSA A, EZENWA M.I.S., OLADIRAN J.A., AKANYA H.O., OGBADOYI E.O. Effect of soil nitrogen levels on some micronutrients, antinutrients and toxic substances in Corchorus olitorius in Minna, Nigeria. Afr. J. of Agric. Res. 5 (22), 3075, 2010.

3. MA H.Y., WANG R.J., WANG X.S, MA H. Identification and evaluation of salt tolerance of jute germaplasm during germination and seedling periods. J. of plant gen. res. 10 (2), 236, 2009.

4. TANEENAH A., NULIT R., YUSOF U.K., JANAYDEH M. Tolerance of Molokhia (Corchorus olitorius L.) Seed with Dead Sea Water, Sea Water, and $\mathrm{NaCl}$ : Germination and Anatomical Approach. Advances in Environmental Biology. 9 (27), 106, 2015

5. LI R., SHI F., FUKUDA K., YANG Y. Effects of salt and alkali stresses on germination, growth, photosynthesis and ion accumulation in alfalfa (Medicago sativa L.). Soil Sci. Plant Nutr. 56 (5), 725, 2010.

6. SHILA A., HAQUE M.A., AHMED R., HOWLADER M.H.K. Effect of different levels of salinity on germination and early seedling growth of sunflower. World Res. J. Agri. Sci. 3 (1), 48, 2016

7. OUZOUNIDOU G., ILIAS I.F., GIANNAKOULA A., THEOHARIDOU I. Effect of water stress and $\mathrm{NaCl}$ triggered changes on yield, physiology, biochemistry of broad bean (Vicia faba) plants and on quality of harvested pods. Biologia. 69 (8), 1010, 2014.

8. GUPTA B., HUNAG B. Mechanism of salinity tolerance in plats: Physiological, Biochemical and Molecular characterization. Int. J. Gen. 2014, 1, 2014.

9. BATES L.S., WALADEREN R.P., TEARE I.D. Rapid determination of free proline of water stress studies. Plant and soil. 39 (1), 205, 1973.
10. DUBOIS M., GILLESK L., HAMILTON J.K., REBERG P.A., SMITH F. Colorimetric method for determination of sugars and related substance. Anal. Chem. 28 (3) 350, 1956.

11. WANG Y., JIANG G.Q., HAN Y.N., LIU M.M. Effects of salt, alkali and salt-alkali mixed stresses on seed germination of the halophyte Salsola ferganica (Chenopodiaceae). Acta Ecologica Sinica, 33 (6), 354, 2013

12. RAZMJOO K., HEYDARIZADEH P., SABZALIAN M.R. Effects if Salinity and Drought on growth parameters and Essential Oil Content of Matricaria chamomile. Int. J. Agr. Biol. 10 (4), 451, 2008.

13. SYVERTSEN J.P., GARCIA-SANCHEZ F. Multiple Abiotic Stresses Occurring with Salinity Stress in Citrus. Environ. Exp. Bot. 103, 128, 2014.

14. THOURAYA R., IMEN I., IMEN H., RIADH I., AHLEM B., HAGER J. Effet du stress salin sur le comportement physiologique et métabolique de trois variétés de piment (Capsicum annuum 1.), J. of Appl. Biosci. 66 (15), 5060, 2013.

15. BHAGIRATH C.S., JOHNSON D.E. Seed germination and seedling emergence of Nalta Jute (Corchorus olitorius) and Red weed (Melochia concatenate). Weed science. 56 (6), 814,2008

16. ODUNNAIKE J.O., AJIBOYE A.A., AGBOOLA D.A. Investigations on the effect of salinity stress on the seedling growth of Corchorus olitorius (L.). Sci Focus. 18 (3), 21, 2013.

17. JAVED S., BUKHARI S.A., ASHRA M.Y., MOHAMED S., IFTIKHAR T. Effect of salinity on growth, biochemical parameters and fatty acid composition in safflower (Carthamus Tinctorius L.). Pak. J. Bot. 46 (4), 1153, 2014.

18. CHAUDHURI K., CHOUDHURI M.A. Effect of shortterm $\mathrm{NaCl}$ on water relations and gaz exchange of two jute species. Biol. plant. 40, 373, 1997.

19. ALAM M.A., JURAIMI A.S., RAFII M.Y., HAMID A.A. Effect of salinity on biomass yield and physiological and stem-root anatomical characteristics of Purslane (Portulaca oleracea L.) accessions. Biomed. Res. Int. 2015 (10), 1, 2015.

20. BACH H., MANSOUR E., GUASMI F., TRIKI T., FERCHICHI A. Proline, glycine bétaïne et composition minérale des plantes de Solanum lycopersicum L. (var. Microtom) sous stress salin. J. of new sci. 22 (3), 1007, 2015.

21. RANGANAYAKULU G.S, VEERANAGAMALLAIAH G., SUDHAKAR C. Effect of salt stress on osmolyte accumulation in two groundnut cultivars (Arachis hypogaea L.) with contrasting salt tolerance. Afr. J. plant sci. 7 (12), 586, 2013 